\title{
Research on the Status of Students' Participation in Sports in Some Private Middle Schools in Qingdao, China
}

\author{
$\mathrm{Li} \mathrm{Liu}^{1}$ \\ ${ }^{1}$ Qingdao University of Science and Technology, Department of Physical Education, Laoshan District, Qingdao, \\ China \\ Correspondence: Li Liu, Qingdao University of Science and Technology, Department of Physical Education, \\ Laoshan District, Qingdao, China. E-mail: 13969851549@163.com
}

Received: June 19, 2014 Accepted: June 23, 2014 Online Published: June 25, 2014

doi:10.5539/ass.v10n13p293

URL: http://dx.doi.org/10.5539/ass.v10n13p293

\begin{abstract}
Via document retrieval, interviews and investigation and other methods, we researched the current situation of the students' participation in physical education in 13 private middle schools in Qingdao, China. According to their own marketing positions, private schools can be classified into three types: The civil schools catering to the labor stratum, relative schools catering to the migration workers, exclusive schools catering to the middle and high level earning families. Through the research to the first two type schools, we find that most of such private schools are run with poor conditions and loose teaching management, the PE teachers' quality is blow, families have little positive influence in the students' participation of sports activities and students' sports participation awareness is not strong, we hope that we can find out some existing problems and propose our feasible suggestions which may improve the current situation of school's physical education.
\end{abstract}

Keywords: private school, participation in physical education, research on current situation

\section{Introduction}

As we know, sport is a component part of school education, and it's also an important content of campus culture construction. It plays an active role in the aspects of improving middle school students' physical fitness and mental health, cultivating their good habits, enhancing their natures of discipline, and this will benefit the students throughout their lives. At present, the participation of middle school students' sports is paid more and more attention by parents, schools and government. However, many poor middle school students often do not get enough exercise opportunity by restrictions, therefore, it has become a urgent problem which need to be solved for every sports workers how we play the positive role of sports activities, make the middle school students in poor families get enough physical exercise in order to make them adapt to the opportunities and challenges in modern social life. This research expounds the survey about the sports participation of poor middle school students in Qingdao, China, analyzes the results of the survey, and find out the reasons. Finally, the author puts forward the countermeasure and suggestion of improving sports activities in poor private middle school.

\section{Method}

\subsection{The Object of the Research}

In this paper, the author takes 13 poor private middle schools in Qingdao, China as the object of the research. They are Qingdao wisdom and honor private middle school, Qingdao Yuwen middle school, Qingdao Binhai private middle school, Qingdao Yuxian private middle school, Qingdao Xinxing middle school, Private Qingdao Galaxy international school, Qingdao Changtai school, Qingdao Ruida private middle school, Qingdao Zhicheng experimental middle school, middle school affiliated to Qingdao University, Qingdao Shanhai private middle school, Qingdao Baishan private middle school, Qingdao Tianlong private middle school.

\subsection{The Research Methods}

\subsubsection{Literature Review Method}

The author collected many domestic and foreign literatures about this research topic, involving pedagogy, sociology, sports, via library document information collection and network resources retrieval. 


\subsubsection{Questionnaire Survey Method}

The author designed a questionnaire according to the research purpose and content, the questionnaire's effectiveness was 0.91 and its reliability was 0.96 after testing. Then the author handed out 320 questionnaires to students in the above Qingdao private schools in all, taken back 298 questionnaires. The return rate was $93.1 \%$, and the proportion of valid questionnaires was $92.8 \%$ among the returned questionnaires.

\subsubsection{Mathematical Statistics Method}

The author processed the data using SPSS 11.0 after collecting the questionnaires.

\section{Results and Analysis}

\subsection{The Situation of Students' Participation in Sports Activities in Qingdao Private Middle Schools}

Table 1. The frequencies of Qingdao private middle school students' participate in sports activities

\begin{tabular}{cccccc}
\hline \multicolumn{7}{c}{ Times of students participation in sports activities / week } \\
\hline Percentage & 0 & $1-2$ & $3-4$ & $5-6$ & $6-$ \\
& 11.4 & 34.6 & 33.9 & 15.8 & 4.3 \\
\hline
\end{tabular}

According to the survey, the frequencies of Qingdao private middle school students' participation in extracurricular sports activities are as follows: The proportion of the students who participate in sports activities 1 to 2 times per week is $34.6 \%$, on the contrary, the proportion of the students participating in sports activities above 6 times is only $4.3 \%$. And there are $11.4 \%$ of students who never participate in sports activities (see Table 1). According to the expressly prescribed regulations of Chinese ministry of education, the primary and middle school students should have daily hours of sports and outdoor activities. This shows that most private middle school students in Qingdao have insufficient sports activities, and the students' sports participation senses need to be strengthened.

\subsection{The Development of Physical Education Curriculum in Qingdao Private Middle Schools}

Table 2. The students' favorite sports

\begin{tabular}{lccccc}
\hline \multicolumn{5}{c}{ The students' favorite sports or curriculum } \\
\hline Percentage & Track and Field & Ball Games & Martial Arts & Sports Dance & Games \\
& 11.4 & 34.6 & 33.9 & 15.8 & 4.3 \\
\hline
\end{tabular}

According to the survey, $40.1 \%$ of students like ball games, such as basketball, table tennis and so on, while there are still $19.3 \%$ of students choosing martial arts classes, and $3.2 \%$ of students choosing sports dance (see table 2). In the private middle schools, the ball games are carried out well, because the environment of the ball games is mobile, and many students can feel the pleasure from them. However, we also find that there are very few schools setting up martial arts and sports dance classes, this reflects the schools' helpless on the other side. Through the surveys and interviews we find that some schools' physical curriculum teachers are replaced by other teachers who didn't receive regular physical education due to the limited power of running and the lack of sports venues and equipment, so it is difficult to let the students learn the correct action skills. In order to give students a sports class under local conditions, many physical education (PE) teachers often make some sports equipment by themselves or adapt some action skills.

\subsection{The Condition of School Sports Facilities and the Organization of School Sports Games}

School sports environment refers to the sum of all the conditions in developing sports activities. Most of the private schools are in a small size and its facilities are also very simple and out of date in the survey sample. Further worse, some of them don't have basic facilities, such as the track fields and basketball court.

Four of the 13 schools didn't organize any sports competition and sports game in the past two years. The reason is that these common and migrant worker schools are generally founded by the individual investment, and lacks of adequate strength. There is no condition to hold an athletic meet for these schools because of the limitation of space and teachers, it is even difficult to achieve interest sports groups often organized by general public schools. 
Most sponsors of these schools are neither the local government nor an enterprise or institution which has "legal education qualification", but some "strangers" becoming prosperous first. These sponsors depend on student's tuition to run the school, in order to maintain the school expense, they need to find the way that is most economical, therefore their education service level is often not in conformity with the national standard.

The floating population schools are refused to be outside in the sports meets organized by the city government due to some limitations, such as household registration and other reasons.

\subsection{Physical Education Curriculum Teaching Methods and the Evaluation of Physical Education Curriculum}

Sports teaching method is a sum of series interacted teaching actives, which is for the sake of achieving the teaching objectives and teaching tasks in the process of teaching under the efforts of teachers and students. It will lead to excessive energy consumption of teachers and students, students' heavy burden, poor teaching effects, and undue losses if teachers can't select and use teaching method scientifically. But many aspects of most private schools can't satisfy the requirement of physical education teaching in reality due to the limited educational condition, the lack of sports equipment. Physical education teachers will teach their students in a negative way, such as sheep herding style teaching, if they could not get self-realization for a long time.

Curriculum evaluation is a process of evaluating the values and characteristics of issues, including course scheme, curriculum implementation and results based on certain methods, standards and ways. A scientific and reasonable evaluation can mobilize the enthusiasm and initiative of students' learning sports, promote the comprehensive development of all students. The form of curriculum should be varied according to different evaluation content. It should not only emphasize the teachers' evaluation to student, but also emphasize the students' self-evaluation and mutual evaluation. In these private middle schools, due to the single teaching methods, the evaluation methods of many teachers are so simple that they affect the students' sports participation motivation in a certain extent.

\section{Reasons}

\subsection{The Strength of the Schools Is Limited}

On the one hand, most of these private schools are for working-class and migrant workers, this leads to the lack of school funds because the workers could not afford a high tuition fee, and causes further that most of sports fields and facilities are humble. On the other hand, some sponsors of the private schools do not spend the education balance money on increasing education investment and improving school conditions according to the relevant provisions of the state, but rather they put the money into their own pockets directly as a personal benefit. This will finally cause that the physical education teaching can't go smoothly and the students had few after-class activities.

\subsection{The Quality and Salary of PE Teachers Is Not High}

The basic task of education is to foster the talents in order to serve the modernization. While the sports teaching task is to enhance students' physique, improve the level of their health, teach students the sports technology, skills and basic knowledge of sports health care, guide students' physical exercise, cultivate the students' interest in sports and their lifelong exercise ability, improve students' sports culture, promote the individuality development of students in an all-round way.

By investigating we find that many private school teachers have the following features: Part-time teachers take the main part of the sports teachers in some small private schools. The problems of strong liquidity, aging and unreasonable age structure in sports teachers are popular in the private schools. What's worse, the quality of the teachers is low.

In the private schools, sport teaching is often in a dispensable position, and the status of the PE teachers is also lower than the other course teacher. This direct reflects in class fee, in most of the schools the PE teachers' class fee is far less than other teachers'. The main reason of the phenomenon is that the entrance exam or major exam is usually measured by the backbone courses, such as Chinese, Maths, while sports is often just a reference, even the value of reference does not exist. Moreover, due to the limitation of teaching conditions, it is hard to take sports teaching according to their expectation for PE teachers. Many PE teachers gradually lose their motivation to constantly improve their teaching, but often take the sheep herding style teaching. Under such circumstances, it is difficult to have a clear teaching goal for PE teachers in the teaching process, and let students form the habit of lifelong sports. 


\subsection{The Students' Awareness Is Weak and They Are Lack of Sports Exercise}

Table 3. The sources of student sports knowledge

\begin{tabular}{|c|c|c|c|c|c|}
\hline \multicolumn{6}{|c|}{ The sources of student sports knowledge } \\
\hline & Course Teaching & TV & Newspaper / Magazine & Extracurricular Activities & Others \\
\hline Percentage & 39.2 & 34.8 & 15.1 & 9.1 & 0.8 \\
\hline
\end{tabular}

The students' sports knowledge is mainly from course teaching and TV media. As shown in the above table, $39.2 \%$ of the sports knowledge is originated from the teaching of physical education, $49.9 \%$ of the sports knowledge is from television media. According to the survey $70.2 \%$ of the school students are $12-14$ years old, these students are lack of subjective judgment and don't understand the positive role of physical exercise due to the small age, this leads to their low enthusiasm and initiative in extracurricular physical exercises. Some students don't realize that it can improve the effects of culture learning with the improvement of physical quality via sports exercise. There are also some other endocentric students who have difficulties to face difficulties in sports exercises. In the investigation of students' spare time allotment (see table 4), the largest proportion is dating entertainment accounting for $27.8 \%$ of the total samples, while the sports activities accounts for $20.9 \%$ of the overall total samples, which is only in the third row. From this we can see that school the proportion of the students who participate in extracurricular sports activities in their spare time is very low, an important reason is that the student's ports knowledge is not enough and the awareness of sports participation is not strong.

Table 4. The Investigation of students' spare time allotment

\begin{tabular}{lccccc}
\hline \multicolumn{5}{c}{ Students' spare time allotment } \\
\hline & Sports activities & Dating entertainment & Reviewing lessons & Doing housework & Others \\
Percentage & 20.9 & 27.8 & 18.6 & 7.3 & 25.4 \\
\hline
\end{tabular}

Among the investigated schools, most of the school students are from the floating population with a bad family economic condition. Personal economic condition not only affects the frequencies of sports participation, but also affects the quality of sports participation. The sports participation frequencies of rich people are larger than the poor people. Personal economic conditions also determines the people's sports consumption level, what kind of economic condition will participate in what level of sports entertainment consumption. Most of our investigated families have a low economic level, and they usually live in the lowest level of the society. As the data shown in below (see table 5), 34.6\% of the families' monthly income is between 1000CNY and $1500 \mathrm{CNY}$, $14.6 \%$ of the families' monthly income is even below $1000 \mathrm{CNY}$. There is $75.7 \%$ of the families' total monthly income below $2000 \mathrm{CNY}$ in all, compared to rural area, the data have a very big enhancement, but the urban migrant workers unlike the people living in the countryside who are self-sufficient to a large extent should solve many other lives problems, such as housing, water and electricity, meal. Under such circumstances, the difficulties can be thought that they come up with a certain amount of money to support their children to engage in sports activities.

\section{Conclusion}

In the interview, we find that most of the school students are eager for the sports activities and equipments of schools urgently because of the narrow of their residences. One student said, "I feel bored at home and like staying in school, I hope our school can have more sports equipments and fields, such as basketball court, football field". But we through the survey find that most private schools can't meet the needs of students.

1) Most of such private schools are run with poor conditions and loose teaching management. Also these schools lack of long-term planning and sports education investment.

2) The teachers' quality in such private schools is generally not high, and the teachers flow very frequently. The status of PE teachers in these private schools are humble, this is bad for letting students form the habit of lifelong sports.

3) Families of the students have little positive influence in their participation of sports activities. Because most of the students' parents in the private schools come from rural areas, they have low cultural quality and 
insufficient understanding of physical activity, coupled with pressure of lives, they generally do not encourage their children to participate in sports activities.

4) Students' awareness of sports participation is not strong and they spend little spare time on doing sports exercise.

\section{Recommendations}

As we can see from the above analysis, the Qingdao private school students' participation in sports is bad, so we put forward the following suggestions. And we hope that a more detailed proposal could be analyzed in a future article.

1) Government should increase the investment in sports education funds, and standardize the management of these private middle schools.

2) The private schools should strengthen the construction of PE teachers' team, and adopt incentive mechanism to improve the teacher's teaching enthusiasm, so as to promote the enthusiasm of students in physical exercise, and cultivate their consciousness of lifelong exercise.

3) A variety of sports activities should be held to make students form good habits of sports.

4) The interaction with students' parents should be strengthened to let the parents know the importance of physical exercise in a certain extent.

\section{References}

Feng, S. D. (2003). The survey of Chinese intellectuals participating in sports activities. Chinese sports science, $5,6-9$

$\mathrm{Fu}$, et al. (2004). Literature review of parents' influence on children's sports participation motivation. Journal of Beijing sports university, 10, 1340-1342.

Li, Q. (2002). Migrant workers and social stratification in China. Beijing: Social sciences academic press.

Lu, Y. Z. (2003). The evaluation of Chinese intellectuals' health and sports participation status. Journal of Shandong Sports Institute, 1, 1-4.

Lv, et al. (1995). Family's influence on middle school students' participate in sports. Journal of Shanghai sports institute, 3, 9-13.

Zheng, Q. (2002). Analysis of main influence factors of sports development in small towns in Shanxi Province. Journal of sports science, 22(5), 27-30.

\section{Copyrights}

Copyright for this article is retained by the author(s), with first publication rights granted to the journal.

This is an open-access article distributed under the terms and conditions of the Creative Commons Attribution license (http://creativecommons.org/licenses/by/3.0/). 